OPEN ACCESS

Edited by:

Carmen Ramírez-Maestre, University of Málaga, Spain

Reviewed by: Joana Almeida,

University of Bedfordshire, United Kingdom

Katherine Henrietta Leith University of South Carolina, United States

*Correspondence: Marcel Wilhelm marcel.wilhelm@uni-marburg.de

Specialty section: This article was submitted to

Health Psychology, a section of the journal Frontiers in Psychology

Received: 08 July 2020 Accepted: 27 April 2021 Published: 01 June 2021

Citation:

Wilhelm $M$ and Euteneuer $F$ (2021) Does Health Literacy Make a Difference? Comparing the Effect of Conventional Medicine Versus

Homeopathic Prescribing on Treatment Credibility and Expectancy.

Front. Psychol. 12:581255. doi: 10.3389/fpsyg.2021.581255

\section{Does Health Literacy Make a Difference? Comparing the Effect of Conventional Medicine Versus Homeopathic Prescribing on Treatment Credibility and Expectancy}

\author{
Marcel Wilhelm ${ }^{1 *}$ and Frank Euteneuer ${ }^{1,2}$ \\ 1 Department of Clinical Psychology and Psychotherapy, Philipps University of Marburg, Marburg, Germany, ${ }^{2}$ Department of \\ Psychology, Clinical Psychology and Psychotherapy, Medical School Berlin, Berlin, Germany
}

Objective: While homeopathic remedies are often used to treat non-specific complaints such as headaches, empirical evidence suggests their treatment effect is due to the placebo effect. Low health literacy seems to be connected to higher use of complementary and alternative medicine (CAM). The aim of this study was to examine what people with occasional headaches expect from conventional medicine or homeopathic remedies and if health literacy interacts with this expectation.

Methods: In this experimental study, $n=582$ participants with occasional headaches were randomized to read one of two vignettes, which described the prescription of either conventional medicine or a homeopathic remedy. Subsequently, the participants were asked to rate treatment credibility and expectancy with regard to their assigned vignette. Health literacy was assessed as a potential moderator.

Results: Participants in the conventional medicine group rated treatment credibility and expectancy higher than in the homeopathic remedy group. Moderation analysis revealed that when being offered conventional medicine, participant reports of treatment credibility and expectancy decreased with lower health literacy, while these outcomes increased with lower health literacy for homeopathic remedies.

Discussion: People with occasional headaches estimate the effectiveness of conventional medication properly. However, health care professionals should pay special attention to patients with low health literacy, as they might need more time and information to give their informed consent.

Keywords: homeopathic remedies, treatment credibility, treatment expectancy, health literacy, expectations

\section{INTRODUCTION}

Homeopathy, as a component of complementary and alternative medicine (CAM), is widely used by the general population (Relton et al., 2017). Homeopathy use worldwide ranges from 0.7 to 9.8\% (12-month prevalence; median: 3.9\%). Empirical evidence suggests that homeopathy does not work beyond the placebo effect (Antonelli and Donelli, 2018). This leads to an ethical dilemma: 
the prescription of homeopathic remedies can be seen as deceptive, when it is recommended as an effective medication (Shaw, 2015). However, prescribers of homeopathy do not actively deceive patients as long as they believe in its effect themselves (Levy et al., 2015). The data show that general practitioners are usually aware of the placebo effect and use a variety of "impure" placebos (substances with potential pharmacological effect; e.g., off-label medication, CAM such as homeopathy, vitamin preparations) in order to achieve psychological treatment effects or for non-specific complaints (Meissner et al., 2012; Howick et al., 2013).

Homeopathy can be dangerous, especially when it replaces evidence-based drugs in severe conditions, such as curable cancer (Johnson et al., 2018b). Even complementary use of homeopathy is associated with a higher risk of death and a higher refusal rate of conventional cancer therapy (Johnson et al., 2018a). The literature on the financial implications of adding homeopathic remedies is ambiguous. Whether costs are reduced or increased seems to depend on the health condition and the studies undertaken (Colas et al., 2015; Ostermann et al., 2015; Kass et al., 2020).

Why do patients use homeopathic remedies? As a placebo treatment, the most important predictor for the effect of homeopathy is treatment expectations (Sanders et al., 2020), which are also an essential part of analgesic drug effects (Bingel et al., 2011). A warm, trustworthy and empathic doctor-patientcommunication is another very important mechanism to foster placebo effects (Schedlowski et al., 2015; Howe et al., 2017). It is also more crucial for clinical benefits of homeopathy than the remedy itself (Brien et al., 2011). Analgesic placebo effects regarding different types of headaches are well proven (de Craen et al., 2000; Nilsson Remahl et al., 2003; Steiner et al., 2003; Macedo et al., 2006; Locher et al., 2017). Headaches are highly prevalent (Stovner and Andree, 2010) and frequently treated with homeopathy (Dossett and Yeh, 2018). Additionally, low health literacy, i.e., the ability to communicate, process, and comprehend basic health information, can lead to unrealistic (Smith et al., 2009) or negative treatment expectations (Hadden et al., 2018) and is hypothesized to be linked to high CAM use (von Conrady and Bonney, 2017).

The aim of this study was thus to examine what people with occasional headaches expect from conventional medicine or homeopathic remedies and in what way health literacy interacts with this expectation.

\section{MATERIALS AND METHODS}

\section{Participants}

Participants $(n=582)$ were recruited via online social network groups and established university mailing lists. Informed consent was obtained from all participants before participation. The study design complied with the principles of Helsinki and was approved by the Institutional Review Board of the Department of Psychology, University of Marburg. Assessment took place via an online survey using https://www.soscisurvey.de. Participants (aged $\geq 18$ years) were eligible to take part in the study if they experienced (at least) occasional headaches. Before starting the experiment, participants completed questionnaires assessing baseline characteristics, information about previous use of analgesics and homeopathic remedies, as well as health literacy.

\section{Experimental Design}

Participants were randomly assigned via Sosci Survey's random generator function to read one of two vignettes. Randomization was done directly after agreeing to and signing the study's informed consent form. The potential scenario in both vignettes was a medical doctor-patient consultation; no traditional homeopath-patient consultation scenario was used. Both vignettes started with the following instruction: "Imagine that lately, you have suffered from occasional headaches. These occur from time to time during the day. The pain is sometimes very uncomfortable and affects your everyday life activities. No matter what you do, the headache keeps coming back. You begin to wish that the headache would subside so that you can manage your life without being affected by pain. You therefore decide to see a doctor and ask for help. You describe your symptoms to the doctor and state that you would like a drug for your headaches. After a detailed discussion and a physical exam, the doctor explains that your headaches are not due to a serious physical illness." The vignette for the conventional medicine condition continued as follows: "He explains to you: I prescribe Ibuprofen, which you take when you experience a headache. It is a widely used and well-known drug for various types of headaches. It is taken in the form of pills. This treatment has helped many of my patients, they feel better now. If your headache occurs, you should take 1-2 tablets." In contrast, the vignette for the homeopathic remedy condition continued as follows: "He explains to you: I prescribe Belladonna, which you take when you experience a headache. It is a widely used and well-known homeopathic remedy for various types of headache. It is taken in the form of globules. This treatment has helped many of my patients, they feel better now. If your headache occurs, you should take five globules." Subsequently, participants were asked to rate treatment credibility and expectancy.

\section{Measurement Instruments}

The Pain Disability Index (PDI; Tait et al., 1987) was used to measure pain-related disability. The seven items of the PDI range from 0 (no disability) to 10 (total disability). The sum of the seven items ranges from 0 to 70 , with higher scores reflecting higher interference of pain with daily activities.

Health literacy was assessed with the short form of the European Health Literacy Questionnaire (HLS EU-Q16; Röthlin et al., 2013). This questionnaire consists of 16 items ranging from 1 (fairly easy) to 4 (very difficult), which assess the ability to access, understand, appraise and apply health information. An overall HLS EU-Q16 index was calculated following the manual for the instrument (Röthlin et al., 2013). For this purpose, item scores were dichotomized, and a sum score was calculated ranging from 0 to 16 . Higher scores indicate higher health literacy.

Treatment credibility and expectancy were assessed using the Credibility/Expectancy Questionnaire (CEQ; 
TABLE 1 | Sample characteristics.

\begin{tabular}{|c|c|c|c|}
\hline Variables & $\begin{array}{l}\text { Conventional } \\
\text { medicine } \\
(n=292)\end{array}$ & $\begin{array}{l}\text { Homeopathy } \\
\qquad(n=290)\end{array}$ & $p$ \\
\hline Age, years & $35.47(13.57)$ & $36.46(14.14)$ & 0.386 \\
\hline Females, $n(\%)$ & 239 (81.8) & 233 (80.3) & 0.301 \\
\hline $\begin{array}{l}\text { Lower/Upper } \\
\text { Secondary school } \\
\text { education }{ }^{1}\end{array}$ & $62 / 223$ & $53 / 233$ & 0.349 \\
\hline $\begin{array}{l}\text { Pain Disability Index } \\
\text { Use of pain agents } \\
\text { if required }\end{array}$ & $25.01(17.02)$ & 24.49 (16.67) & 0.706 \\
\hline $\begin{array}{l}\text { Conventional } \\
\text { analgesics, } n(\%)\end{array}$ & 243 (83.2) & 235 (81.0) & 0.517 \\
\hline $\begin{array}{l}\text { Homeopathic } \\
\text { remedies, } n(\%)\end{array}$ & $18(0.1)$ & $25(0.1)$ & 0.271 \\
\hline Health Literacy & 11.01 (3.28) & 11.29 (3.29) & 0.318 \\
\hline $\begin{array}{l}\text { Post-manipulation } \\
\text { treatment credibility }\end{array}$ & $14.56(6.28)$ & $11.13(7.08)$ & $<0.001$ \\
\hline $\begin{array}{l}\text { Post-manipulation } \\
\text { treatment } \\
\text { expectancy }\end{array}$ & $14.03(6.90)$ & $10.50(7.17)$ & $<0.001$ \\
\hline
\end{tabular}

Values shown as mean (SD) unless otherwise noted. Group differences were calculated using t-tests and $\chi 2$ tests as appropriate. ${ }^{1}$ Lower secondary education refers to German school leaving examinations from a general secondary school [Hauptschulabschluss] or a secondary school [Mittlere Reife]; upper secondary education refers to a range of German school leaving examinations which enable university entrance [Fachhochschulreife, fachgebundene Hochschulreife, allgemeine Hochschulreife].

Devilly and Borkovec, 2000). The subscale for credibility captures how believable, convincing, and logical the treatment is, and the subscale for expectancy assesses how much the participants expect that the treatment will alleviate their headache. Each subscale consists of three items ranging from 1 or $0 \%$ (logical/useful/confident) to 9 or $100 \%$ (very logical/useful/confident), depending upon the item. The total score ranges from 2 to 27 where higher scores indicate higher credibility and expectancy, respectively.

\section{Statistical Analysis}

Statistical analysis was carried out with Mplus7 (Muthén and Muthén, 2012) and IBM SPSS version 23.0 for Windows (Chicago, SPSS, Inc.). Group differences were assessed using $t$-tests (if necessary, with Welch's correction). A path analysis with full information maximum likelihood estimation and 10,000 bootstraps was performed to simultaneously examine lower order effects and the interaction effect between settings (i.e., conventional medicine vs. homeopathy) and health literacy on both outcomes (i.e., treatment credibility, treatment expectancy).

\section{RESULTS}

Mean age of the 582 participants was 35.96 years $(S D=13.86$, range: 18 -95 years). The sample consisted of 472 women $(81.10 \%)$ and most participants had upper secondary school education $(74.78 \%$ with upper secondary school education). There were no significant differences in participant characteristics between the two experimental groups prior to the reading of vignettes. Table 1 shows sample characteristics for baseline variables and outcome measures separated by group.

Compared to individuals asked to imagine being offered conventional medicine, participants asked to imagine being offered a homeopathic remedy reported lower levels of treatment credibility, $t(570.96)=6.16, p<0.001$, and treatment expectancy, $t(580)=6.06, p<0.001$. However, health literacy had an impact on group differences in treatment credibility $(\beta=-0.61$, $p=0.001)$ and treatment expectancy $(\beta=-0.62, p=0.001)$. Reported treatment credibility and expectancy for participants asked to imagine being offered conventional medicine decreased

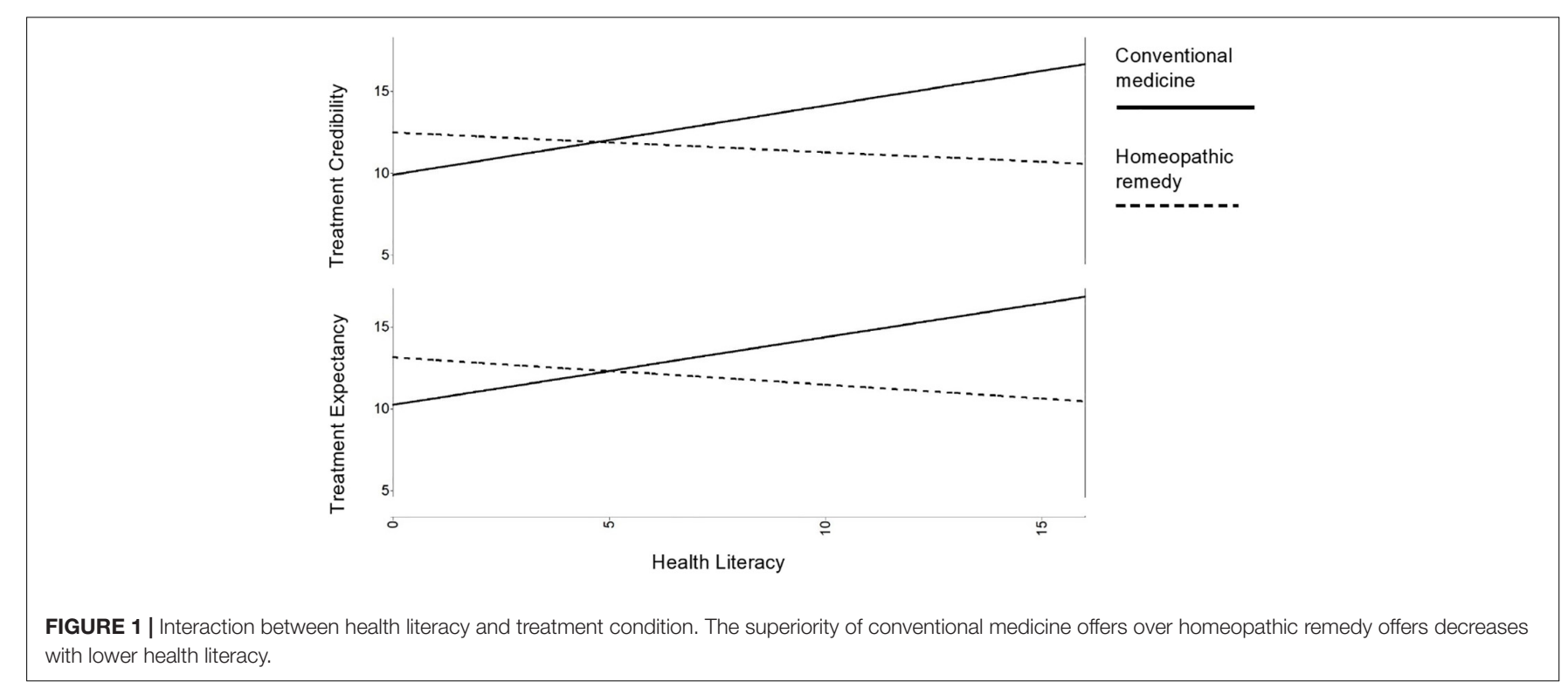


with lower health literacy, while they increased with lower health literacy for participants asked to imagine being offered homeopathic remedies. Thus, the perceived superiority of conventional medicine offers over homeopathic remedy offers with respect to treatment credibility and expectancy increased with higher health literacy. Figure 1 plots these interactions.

\section{DISCUSSION}

In this study, participants in the conventional medicine group rated treatment credibility and expectancy higher compared to participants in the homeopathic remedy group. In the conventional medicine group, participant reports of treatment credibility and expectancy decreased with lower health literacy, while these outcomes increased with lower health literacy in the homeopathic remedy group. Thus, the perceived superiority of conventional medicine offers over homeopathic remedy offers regarding treatment credibility and expectancy increased with higher health literacy.

The results appear to be robust, as the large sample matches the prevalence of headaches with predominantly female participants and a mean age between 20 and 50 years and a substantial pain disability due to occasional headaches (Stovner and Andree, 2010). Participants only received one vignette and were not aware of another treatment or group. Therefore, the data are not confounded by intraindividual comparisons between the two treatment vignettes.

These results show that people with high health literacy tend to expect less relief from homeopathic remedies than those with low health literacy, and they emphasize the importance of identifying patients with low health literacy early in the treatment process. These patients tend to need more attention and explanation but tend to receive less time during doctor visits (Menendez et al., 2016). Improved communication by physicians is therefore necessary to inform these patients more comprehensively. Homeopaths match these needs, as their communication style is more participatory and allows longer consultations (Marian et al., 2008). Doctor-patient-communication is of importance for subjective and objective health outcomes (Riedl and Schüßler, 2017). Conventional medical treatments must improve - not in terms of consultation length per se, but in terms of quality of the participatory engagement as a key part of a successful doctor-patient-relationship (Ha, 2010).

A remaining issue is if patients with low health literacy can give informed consent, without being explicitly informed about the placebo-like character of the treatment. There is broad evidence that open-label placebos work (Kaptchuk and Miller, 2018). Giving a plausible (placebo) treatment rationale is more important than deception (Locher et al., 2017). Describing homeopathic remedies as placebo treatments should therefore be possible without the fear of losing its effect. Additionally,

\section{REFERENCES}

Antonelli, M., and Donelli, D. (2018). Reinterpreting homoeopathy in the light of placebo effects to manage patients who seek homoeopathic care: a identifying low health literacy patients and supporting them, e.g., via health education programs, health communication trainings, or extended doctor visits, should be a focus of future research.

A few limitations should be discussed. The setting of both vignettes resemble situations of conventional medicine prescriptions and might therefore be in favor of the conventional medicine group. Consultation time of a homeopathic physician can take twice as long as the consultation time of a conventional physician (Bishop et al., 2007; Marian et al., 2008). The situations were only described via text. However, when used appropriately, vignette studies show satisfying internal, external, and construct validity (Evans et al., 2015). On the other hand, two more vignettes using a homeopathic setting could have provided more information. But as the doctor-patient-communication is a very important ingredient of homeopathic treatment (Brien et al., 2011), the text based vignettes could still have disadvantaged homeopathic prescribing. Future studies should use real interactions or video sessions to address this issue. While this limitation might have influenced the intergroup effect in favor of the conventional medicine group, the interaction with health literacy appears even more striking. The results should still be interpreted with caution, as a high level of education and the high number of female participants could have affected them.

In conclusion, individuals seem to be able to properly estimate the effectiveness of evidence-based conventional medication, unless their health literacy is low. Spending more consultation time with patients to explain treatment options without any deception is an important responsibility for health care professionals.

\section{DATA AVAILABILITY STATEMENT}

The datasets presented in this article are not readily available due to missing consent of the participants. Requests to access the datasets should be directed to Dr. Marcel Wilhelm (Email: marcel.wilhelm@uni-marburg.de).

\section{ETHICS STATEMENT}

The studies involving human participants were reviewed and approved by Ethics Committee of the Department of Psychology, University of Marburg. The patients/participants provided their written informed consent to participate in this study.

\section{AUTHOR CONTRIBUTIONS}

Both authors listed have made a substantial, direct and intellectual contribution to the work, and approved it for publication.

systematic review. Health Soc. Care Community 27, 824-847. doi: 10.1111/hsc. 12681

Bingel, U., Wanigasekera, V., Wiech, K., Ni Mhuircheartaigh, R., Lee, M. C., Ploner, M., et al. (2011). The effect of treatment expectation on drug efficacy: imaging 
the analgesic benefit of the opioid remifentanil. Sci. Transl. Med. 3:70ra14. doi: 10.1126/scitranslmed.3001244

Bishop, F. L., Yardley, L., and Lewith, G. T. (2007). A systematic review of beliefs involved in the use of complementary and alternative medicine. J. Health Psychol. 12, 851-867. doi: 10.1177/1359105307082447

Brien, S., Lachance, L., Prescott, P., McDermott, C., and Lewith, G. (2011). Homeopathy has clinical benefits in rheumatoid arthritis patients that are attributable to the consultation process but not the homeopathic remedy: a randomized controlled clinical trial. Rheumatology 50, 1070-1082. doi: 10.1093/ rheumatology/keq234

Colas, A., Danno, K., Tabar, C., Ehreth, J., and Duru, G. (2015). Economic impact of homeopathic practice in general medicine in France. Health Econ. Rev. 5, 55-55. doi: 10.1186/s13561-015-0055-5

de Craen, A. J. M., Tijssen, J. G. P., de Gans, J., and Kleijnen, J. (2000). Placebo effect in the acute treatment of migraine: subcutaneous placebos are better than oral placebos. J. Neurol. 247, 183-188. doi: 10.1007/s00415 0050560

Devilly, G. J., and Borkovec, T. D. (2000). Psychometric properties of the credibility/expectancy questionnaire. J. Behav. Ther. Exp. Psychiatry 31, 73-86. doi: 10.1016/S0005-7916(00)00012-4

Dossett, M., and Yeh, G. (2018). Homeopathy use in the united states and implications for public health: a review. Homeopathy 107, 003-009. doi: 10. 1055/s-0037- 1609016

Evans, S. C., Roberts, M. C., Keeley, J. W., Blossom, J. B., Amaro, C. M., Garcia, A. M., et al. (2015). Vignette methodologies for studying clinicians' decisionmaking: validity, utility, and application in ICD-11 field studies. Int. J. Clin. Health Psychol. 15, 160-170. doi: 10.1016/j.ijchp.2014.12.001

Ha, J. F. (2010). Doctor-patient communication: a review. Ochsner J. 10, 38-43.

Hadden, K. B., Prince, L. Y., Bushmiaer, M. K., Watson, J. C., and Barnes, C. L. (2018). Health literacy and surgery expectations in total hip and knee arthroplasty patients. Patient Educ. Couns. 101, 1823-1827. doi: 10.1016/j.pec. 2018.05.021

Howe, L. C., Goyer, J. P., and Crum, A. J. (2017). Harnessing the placebo effect: exploring the influence of physician characteristics on placebo response. Health Psychol. 36, 1074-1082. doi: 10.1037/hea0000499

Howick, J., Bishop, F. L., Heneghan, C., Wolstenholme, J., Stevens, S., Hobbs, F. D. R., et al. (2013). Placebo use in the United Kingdom: results from a national survey of primary care practitioners. PLoS One 8:e58247. doi: 10.1371/ journal.pone.0058247

Johnson, S. B., Park, H. S., Gross, C. P., and Yu, J. B. (2018a). Complementary medicine, refusal of conventional cancer therapy, and survival among patients with curable cancers. JAMA Oncol. 4, 1375-1381. doi: 10.1001/jamaoncol.2018. 2487

Johnson, S. B., Park, H. S., Gross, C. P., and Yu, J. B. (2018b). Use of alternative medicine for cancer and its impact on survival. J. Natl. Cancer Inst. 110, 121-124. doi: 10.1093/jnci/djx145

Kaptchuk, T. J., and Miller, F. G. (2018). Open label placebo: can honestly prescribed placebos evoke meaningful therapeutic benefits? BMJ 363:k3889. doi: $10.1136 /$ bmj.k3889

Kass, B., Icke, K., Witt, C. M., and Reinhold, T. (2020). Effectiveness and cost-effectiveness of treatment with additional enrollment to a homeopathic integrated care contract in Germany. BMC Health Serv. Res. 20:872. doi: 10. 1186/s12913-020-05706-4

Levy, D., Gadd, B., Kerridge, I., and Komesaroff, P. A. (2015). A gentle ethical defence of homeopathy. J. Bioeth. Inq. 12, 203-209. doi: 10.1007/s11673-0149563-y

Locher, C., Nascimento, A. F., Kirsch, I., Kossowsky, J., Meyer, A., and Gaab, J. (2017). Is the rationale more important than deception? A randomized controlled trial of open-label placebo analgesia. Pain 158, 2320-2328. doi: 10.1097/j.pain.0000000000001012

Macedo, A., Farré, M., and Baños, J.-E. (2006). A meta-analysis of the placebo response in acute migraine and how this response may be influenced by some of the characteristics of clinical trials. Eur. J. Clin. Pharmacol. 62, 161-172. doi: 10.1007/s00228-005-0088-5
Marian, F., Joost, K., Saini, K. D., von Ammon, K., Thurneysen, A., and Busato, A. (2008). Patient satisfaction and side effects in primary care: an observational study comparing homeopathy and conventional medicine. BMC Complement. Altern. Med. 8:52. doi: 10.1186/1472-6882-8-52

Meissner, K., Hofner, L., Fassler, M., and Linde, K. (2012). Widespread use of pure and impure placebo interventions by GPs in Germany. Fam. Pract. 29, 79-85. doi: 10.1093/fampra/cmr045

Menendez, M. E., Parrish, R. C., and Ring, D. (2016). Health literacy and time spent with a hand surgeon. J. Hand Surg. 41, e59-e69. doi: 10.1016/j.jhsa.2015.12.031

Muthén, L. K., and Muthén, B. O. (2012). 1998-2012. Mplus User's Guide. Los Angeles, CA: Muthén \& Muthén.

Nilsson Remahl, A., Laudon Meyer, E., Cordonnier, C., and Goadsby, P. (2003). Placebo response in cluster headache trials: a review. Cephalalgia 23, 504-510. doi: 10.1046/j.1468-2982.2003.00531.x

Ostermann, J. K., Reinhold, T., and Witt, C. M. (2015). Can additional homeopathic treatment save costs? A retrospective cost-analysis based on 44500 insured persons. PLoS One 10:e0134657. doi: 10.1371/journal.pone.0134657

Relton, C., Cooper, K., Viksveen, P., Fibert, P., and Thomas, K. (2017). Prevalence of homeopathy use by the general population worldwide: a systematic review. Homeopathy 106, 69-78. doi: 10.1016/j.homp.2017.03.002

Riedl, D., and Schüßler, G. (2017). The influence of doctor-patient communication on health outcomes: a systematic review. Z. Psychosom. Med. Psychother. 63, 131-150. doi: 10.13109/zptm.2017.63.2.131

Röthlin, F., Pelikan, J., and Ganahl, K. (2013). Die Gesundheitskompetenz der 15-jährigen Jugendlichen in Österreich. Abschlussbericht der österreichischen Gesundheitskompetenz Jugendstudie im Auftrag des Hauptverbands der österreichischen Sozialversicherungsträger (HVSV). Wien: Ludwig Boltzmann Institut Health Promotion Research (LBIHPR).

Sanders, A. E., Slade, G. D., Fillingim, R. B., Ohrbach, R., Arbes, S. J., and Tchivileva, I. E. (2020). Effect of treatment expectation on placebo response and analgesic efficacy: a secondary aim in a randomized clinical trial. JAMA Netw. Open 3:e202907. doi: 10.1001/jamanetworkopen.2020.2907

Schedlowski, M., Enck, P., Rief, W., and Bingel, U. (2015). Neuro-bio-behavioral mechanisms of placebo and nocebo responses: implications for clinical trials and clinical practice. Pharmacol. Rev. 67, 697-730. doi: 10.1124/pr.114.009423

Shaw, D. (2015). A Strong remedy to a weak ethical defence of homeopathy. J. Bioeth. Inq. 12, 549-553. doi: 10.1007/s11673-015-9674-0

Smith, S. K., Dixon, A., Trevena, L., Nutbeam, D., and McCaffery, K. J. (2009). Exploring patient involvement in healthcare decision making across different education and functional health literacy groups. Soc. Sci. Med. 69, 1805-1812. doi: 10.1016/j.socscimed.2009.09.056

Steiner, T., Lange, R., and Voelker, M. (2003). Aspirin in episodic tensiontype headache: placebo-controlled dose-ranging comparison with paracetamol. Cephalalgia 23, 59-66. doi: 10.1046/j.1468-2982.2003.00470.x

Stovner, L. J., and Andree, C. (2010). Prevalence of headache in Europe: a review for the Eurolight project. J. Headache and Pain 11, 289-299. doi: 10.1007/s10194010-0217-0

Tait, R. C., Pollard, C. A., Margolis, R. B., Duckro, P. N., and Krause, S. J. (1987). The pain disability index: psychometric and validity data. Arch. Phys. Med. Rehabil. 68, 438-441.

von Conrady, D. M., and Bonney, A. (2017). Patterns of complementary and alternative medicine use and health literacy in general practice patients in urban and regional Australia. Aust. Fam. Physician 46, 315-320.

Conflict of Interest: The authors declare that the research was conducted in the absence of any commercial or financial relationships that could be construed as a potential conflict of interest.

Copyright $\odot 2021$ Wilhelm and Euteneuer. This is an open-access article distributed under the terms of the Creative Commons Attribution License (CC BY). The use, distribution or reproduction in other forums is permitted, provided the original author(s) and the copyright owner(s) are credited and that the original publication in this journal is cited, in accordance with accepted academic practice. No use, distribution or reproduction is permitted which does not comply with these terms. 